\title{
Study Health and Safety Workplace in Small and Medium Size Enterprises (HSW-SMEs) in Iran, 2015
}

\author{
Zamanian $\mathrm{Z}, \mathrm{PhD}^{1}$, Mehrifar $\mathrm{Y}, \mathrm{MSc}^{2 *}$ \\ 1- Associate Prof., Research Center for Health Sciences, Shiraz University of Medical Sciences, Shiraz, Iran. 2- MSc \\ Student in Occupational Health Engineering, Student Research Committee, School of Health Sciences, Isfahan University of \\ Medical Sciences, Isfahan, Iran.
}

\begin{abstract}
Received: December 2016, Accepted: February 2017

Background: Today, the growth of major industries depends on their appropriate interaction with small and medium enterprises (SMEs). In Iran, SMEs have 49 or fewer employees. The present study was an attempt to present an overall view of the condition of professional health and safety in such industries in order to gain information regarding activities related to occupational health and safety.

Materials and Methods: This study was a cross-sectional enquiry, in which 541 SMEs in Arak, Iran, were selected through systematic sampling and questionnaires were mailed to these companies. The questionnaires were sent to the occupational health units of the health centers in order to investigate target industries. The collected data was entered into SPSS software and analyzed using descriptive statistical methods.

Results: The total response rate of the SMEs was 59\%. Approximately, 59.2\% of the enterprises monitored their workplace every 6 months in order to reduce and control risks. In addition, $44 \%$ of the target enterprises had written and regulated health and safety policies. With respect to safety, $64.7 \%$ of the enterprises had included health and safety training in the work plans of all employees at all levels. Moreover, $72.3 \%$ trained their staff on how to use self-protection devices, and $69.7 \%$ of the target SMEs had safety and technical protection committees.

Conclusion: Welfare facilities and health management in SMEs were satisfactory. With respect to safety management, it can be inferred from this study that the essential safety and health factors for SMEs include announcing and investigating accidents, and education safety, because $70 \%$ of the target enterprises performed these activities.
\end{abstract}

Keywords: Occupational Health, Safety, Workplace

\section{Introduction}

With the emergence of new technologies in production and communication, there have been developments in production and distribution methods and the organizational structure of enterprises which have added to the importance of small and medium enterprises (SMEs). Hence, governments have adopted special policies to enhance SMEs (1). SMEs which are mostly owned by the private sector play a important role in the country's industrial performance. In recent years, the importance and role of SMEs has increased both in developed and developing countries. Experience has proven that the competitiveness of major industries is dependent on their appropriate interaction with SMEs (1).

The first joint committee of the World Health Organization (WHO) and the International Labor Organization (ILO) which was established in 1950 has defined safety and health as the provision and enhancement of the highest level of physical, mental, and psychological health for laborers in all careers, prediction of work-related diseases and accidents, use of the workforce in an appropriate environment and jobs which they

\footnotetext{
* Corresponding author: Younes Mehrifar, Student Research Committee, School of Health Sciences, Isfahan University of Medical Sciences, Isfahan, Iran.

E-mail: ymehrifar@yahoo.com
} 
are physically and mentally capable of doing, and, in summary, the matching of individuals to occupations (2). SMEs are defined differently in different countries and parts of the world. In fact, what define SMEs in a country are the economic and industrial conditions governing that country. The criteria often used to define SMEs include the number of employees, amount of capital, total sales volume, and production capacity (3).

The most common criterion for defining SMEs, however, is the number of employees. Although there is no single definition for SMEs in Iran, the present study adopts the definition offered by the Iranian Statistical Center which defines SMEs as enterprises with 49 or fewer employees (1-49 employees) (3). Most economic companies comprise SMEs and include a great proportion of companies in many countries. For instance, in the European Union, small enterprises (11-50 members) constitute $98.7 \%$ of all companies and $50.2 \%$ of the workforce employment, whereas SMEs (less than or equal to 250 employees) constitute only $1.3 \%$ of all companies and $49.8 \%$ of the workforce employment (4). The European Commission (2004) estimated that $82 \%$ of occupational injuries and $90 \%$ of fatal accidents occur in SMEs although less than $70 \%$ of the workforce is employed in them (4).

About 33\% of individuals' lifetime is spent at their workplace (5). Despite numerous different conditions of employees of different economic sectors, according to the statistics issued by the ILO, two-thirds of the world's employed population work in environments lacking in minimum safety and health standards (5). Moreover, 60 to $85 \%$ of the society's active workforce in developing countries and 40 to $50 \%$ of this workforce in developed countries work in SMEs or workshops (5). In 2011, the small and medium workshops of Isfahan Province, Iran, created the highest value added, amounting to 7501.2 billion Rials (14.53\%), and the highest production value, amounting to 22800 billion Rials (13.27\%), in comparison to other provinces (6). According to the reports of valid international organizations, such as the ILO, WHO, Occupational Safety and Health Administration (OSHA), and National Institute for Organizational Safety and Health (NIOSH), with respect to work safety and health, SMEs are faced with numerous problems (7). These problems include long work hours, lack of establishment of occupational safety and health committees, lack of insurance coverage for staff, lack of health and healthy facilities, lack of a comprehensive plan for controling detrimental occupational factors of the workplace, and etcetera (7). In 2008, About 2.34 million people were killed in work-related accidents, 2.02 cases of which were due to work-related diseases (8). In England, supporting the issues of occupational health and safety management in SMEs is still at the top of the agenda of the Health and Safety Commission of this country, and many supporting measures have been taken to enhance this procedure (9). In addition, in SMEs where the safety and health elements have been applied, organizational performance has been improved (10). In a study by Vassie et al. in Valencia, Spain, and the Midlands, England, only $35.1 \%$ of the SMEs in Valencia and $71.5 \%$ of the SMEs in the Midlands were aware of work safety and health laws (11). They also found that SMEs in England and Spain devoted little time (3 to 5 hours a week) to work safety and health issues (11).

The study by Kongtip et al. (2008) in Thailand showed the excellent condition of safety and health management in SMEs of this country (12). They indicated that the majority (90\%) of these enterprises are equipped with a system for recording, reporting, and investigation of work accidents and $92.9 \%$ of them conduct regular safety inspections (12). The study by Wei et al. revealed that only $23.9 \%$ of the staff of small enterprises had been trained on work safety and health (13). The study by Hyesook Park et al. demonstrated that in Soule, Korea, the rate of work-related diseases in small enterprises was $5.4 \%$ which was higher than 
the average of international statistics (i.e. $3.5 \%)$ (14).

A study conducted by Taheri (2006) on small enterprises of Sabzevar City, Iran, demonstrated that small industries, in comparison with medium and major industries, have better conditions in terms of health facilities, safety-related accidents, and workforce harmful factors (5). The study also found that the low level of awareness of occupational safety issues has a significant relationship with low education level and old age (5). The study by Kalantari et al. on the condition of occupational health in the workshops of Isfahan in 2001 demonstrated that $36.2 \%$ of the individuals were unaware of the diseases related to their jobs, and $28 \%$ were unaware of personal protective equipment (PPE) for their jobs (15).

Investigations on the number of small and medium industrial workshops in different provinces of Iran demonstrate that, of all the small and medium workshops, $7.5 \%$ are located in Arak Province (6). Reducing work hazards and injuries in these workshops is an indispensable necessity. Considering the necessity of occupational safety and health in SMEs and the lack of a larger scale comprehensive study (incorporating SMEs) either in the country or in Arak Province, the present study attempted to investigate the condition of occupational safety and health management and present an overview of the condition of occupational health in SMEs of Isfahan. It was hoped that the results could offer the necessary information for planning to optimize the aforementioned workplaces and prevent work-related diseases and injuries.

\section{Materials and Methods}

This descriptive study was carried in the spring of 2015. The target group was SMEs (49 or fewer members) in Arak. The information regarding addresses, types of companies, number of employees, and products were obtained from Iran's Ministry of Industries and Mines. Using systematic sampling, 620 SMEs were selected and the questionnaires were mailed to them. The questionnaires were sent to the occupational health units of the health centers to investigate the target industries.

The questionnaire included 5 parts related to the company, welfare-health facilities, management and implementation of occupational safety and health, safety and health training, and aspects of occupational health (electricity safety, fire safety, ergonomics, and etcetera)

A structured questionnaire, prepared in Persian, was used for data collection. To ensure of its reliability, the questionnaire was distributed among 45 employees with the inclusion criteria and the Cronbach's $\alpha$ coefficient of the questionnaire was calculated as $0.72,0.84,0.80,0.86$, and 0.71. To determine its content validity, the questionnaire was sent to 8 occupational health experts and their corrective opinions were applied.

The collected data was then entered into SPSS software (version 19, SPSS Inc., Chicago, IL, USA) and analyzed using descriptive statistical methods.

\section{Results}

In total, 541 SMEs responded (87.25\%) from among 620 SMEs. The distribution of the companies' responses in terms of size (number of employees) is displayed in figure 1.

The results showed that 56 out of the total of 541 responses were from companies with more than 50 members. Therefore, those responses were eliminated. 42 companies had less than 10 employees, and hence, were placed in the group of small companies.

Those industries were electric circuits, machinery, clothing, natural rubber, rubber products, iron, chemicals, textile, shoe, and etcetera industries. Among these companies, rubber and plastic companies gave the most responses. The next industry was engineering which comprised iron products, machinery, and accessories. 


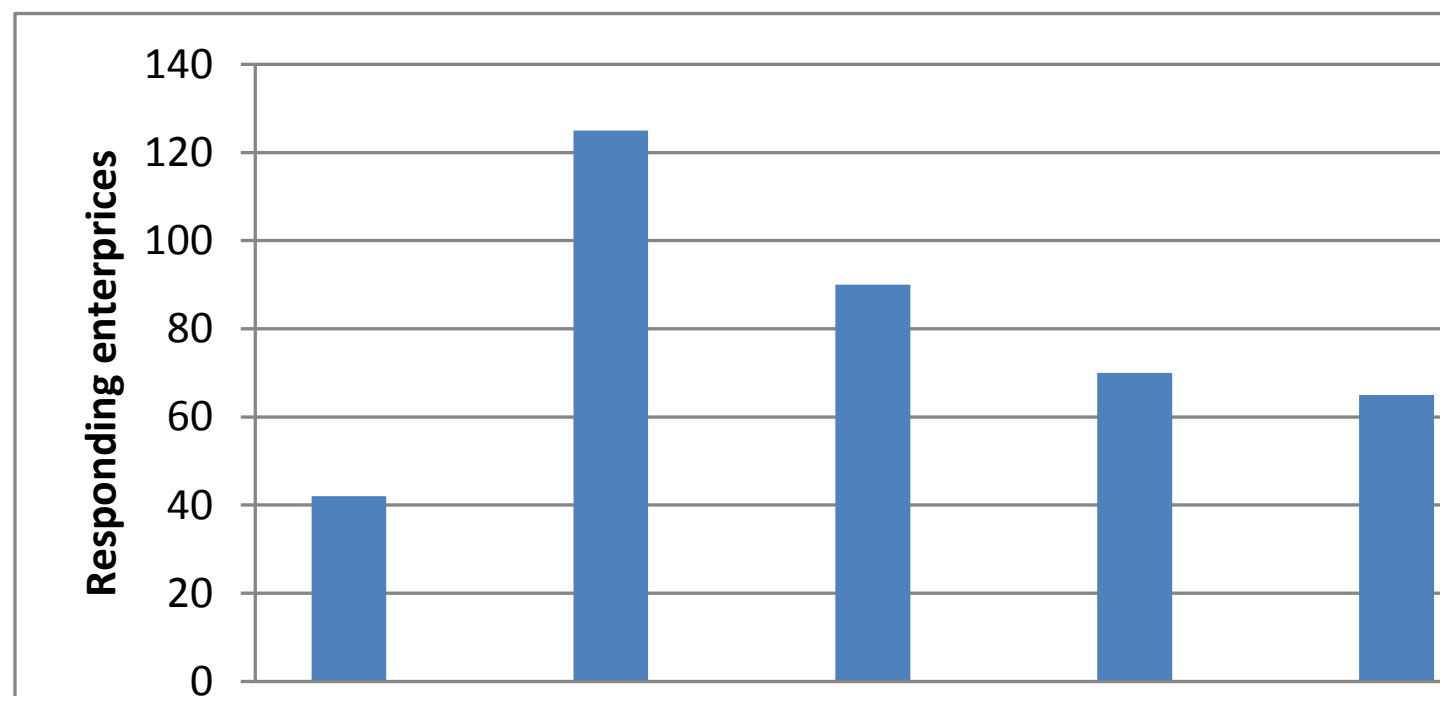

Figure 1: Distribution of responding enterprises according to the number of employees

Workforce characteristics in SMEs: In the target industries, the average ages of young and old male workers were 21.5 and 44.6 years, respectively, and the average ages of young and old female workers were 21.7 and 42.2 years, respectively. The average work hours were 8 hours per day $(92.1 \%)$ and 47.2 hours per week. In each day, $56.6 \%$ of a $60-$ minute rest is spent on dinner and $8.5 \%$ of a 15 -minute rest is spent on breakfast. The daily work schedule of the target enterprises covered a 1-3-shift period. Each shift lasted 7.9 hours on average. Furthermore, on average, 161 companies $(62.2 \%)$ had an overtime of 17.6 hours per week and about 260 hours per week.

Welfare facilities and equipment: Most of the SMEs provided amenities for their staff including healthy drinking water and piping
(98.6\%), sanitary cafeterias and dining halls $(48.2 \%)$, sanitary and clean toilets $(86.5 \%)$, a place for the staff to rest $(69.1 \%)$, and a place for changing clothes (77.9\%) in the company.

Fire prevention: About $71.3 \%$ of the SMEs had special operational programs for fire prevention (Table 1). The results demonstrated that, in $66.1 \%$ of the companies, the sound of the fire alarm system was clearly audible for the workers. Fire detection and fire alarm systems create a loud sound signal different from other workplace signals for early diagnosis. Almost $87 \%$ of the SMEs had provided the necessary training on how to tackle fire for at least $40 \%$ of their staff, and about $77.1 \%$ of the companies had offered written and regular trainings on how to evacuate people during fire.

Table 1: Percentage of enterprises providing fire prevention

\begin{tabular}{ll}
\hline Fire prevention & SMEs (\%) \\
\hline Fire escape route & 59 \\
\hline Fire extinguishing equipment & 86.6 \\
\hline Plan and fire alarm & 7.85 \\
\hline Regular maintenance of fire equipment & 72.3 \\
\hline Fire extinguishing personnel training for at least 40\% of workers & 87 \\
\hline Fire drill and evacuation at least once a year & 77.1 \\
\hline
\end{tabular}

Electricity safety management: The results revealed that $69.8 \%$ of SMEs had a full plan or map of their electric system and circuitry which was approved by the local power office and $51.7 \%$ of SMEs had alarm signals in places exposed to electrocution (Table 2). 
About $83.6 \%$ of the companies had signals, labels, or notices which read 'electrocution danger'. In addition, $52.5 \%$ of the staff of the enterprises had received the necessary training on first aid and relief measures during the occurrence of electric shock incidents.

Table 2: Percentage of enterprises with electricity safety equipment

\begin{tabular}{ll}
\hline Electricity shock prevention & SMEs (\%) \\
\hline Plan of electric circuit & 69.8 \\
\hline Properly maintained electric wire and equipment & 71 \\
\hline Electricity warning sign & 51.7 \\
\hline Locking and tag & 51 \\
\hline Personal protective equipment & 67.1 \\
\hline Training of electricity hazards and first aid & 52.5 \\
\hline
\end{tabular}

Workplace risks: Of all target enterprises, $45.41 \%$ were exposed to chemicals, $66.1 \%$ to noise, and $51.4 \%$ to heat, and $44.3 \%$ of those enterprises assigned monotonous work to their workers (Figure 2).

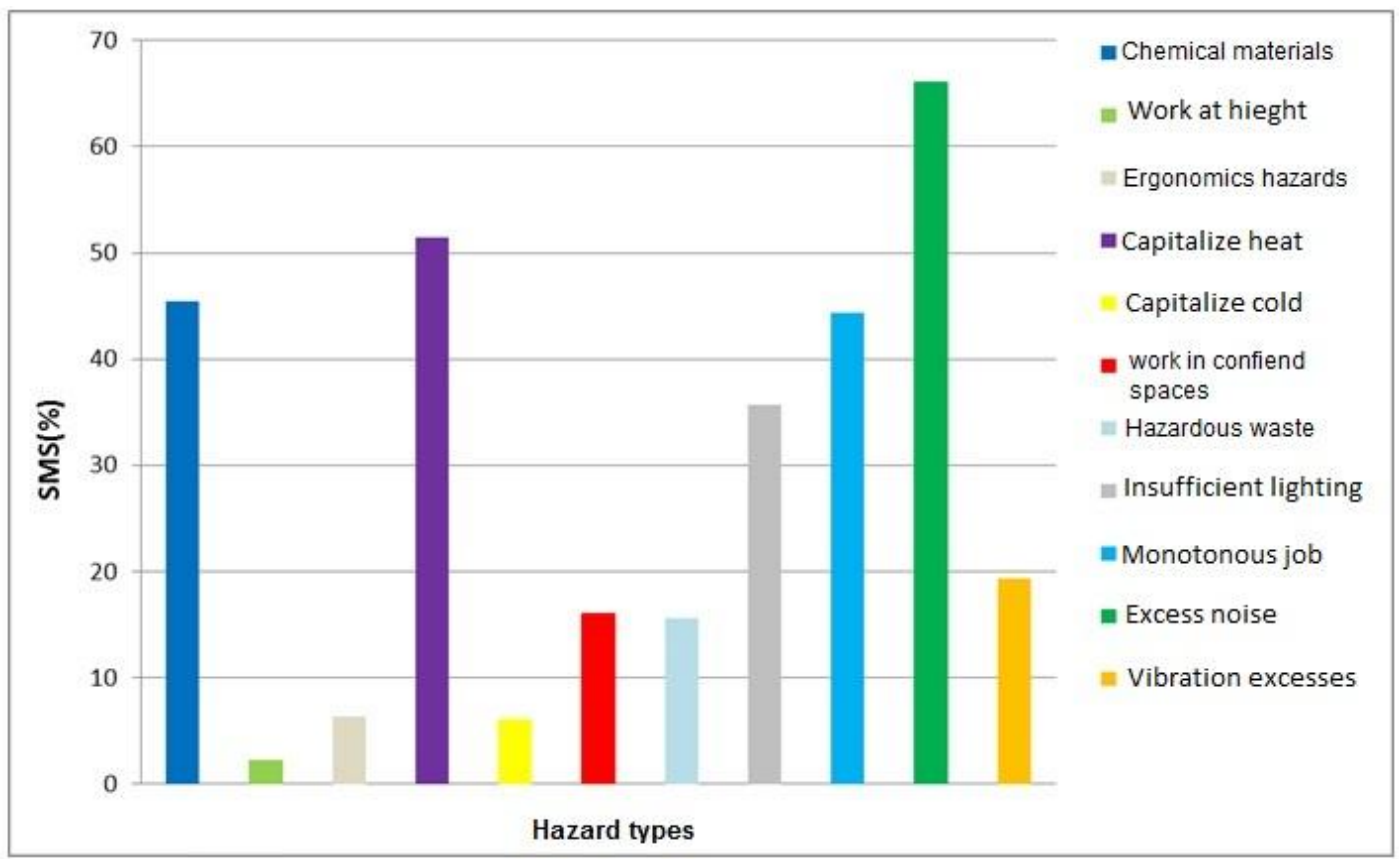

Figure 2: Percentage of enterprises exposed to hazardous working environments

Controlling workplace hazards: Workplace hazards in SMEs under study were controlled and reduced through engineering and paper methods. The results revealed that $65 \%$ of the companies had plans for reducing dust and
$82.2 \%$ had a ventilation system or ventilation fans (Table 3). Staff job rotation was conducted in $52.5 \%$ of the cases, and $88.2 \%$ of the companies provided appropriate PPE.

Table 3: Percentage of enterprises controlling industrial hazards

\begin{tabular}{ll}
\hline Workplace hazards control & SMEs (\%) \\
\hline Ventilation system & 82.2 \\
\hline Measuring vibration & 20.71 \\
\hline Dust control & 65 \\
\hline Measuring noise & 66.5 \\
\hline Providing personal protective equipment for workers & 88.2 \\
\hline Work-rest cycle & 52.5 \\
\hline
\end{tabular}


Occupational safety and health management and training: Occupational safety and health management is crucial in the prevention of work-related incidents and diseases. Table 4 shows that $44 \%$ of the enterprises had written occupational safety and health policies, and in $65 \%$ of the cases, the companies had informed their staff of those policies. In addition, $56.3 \%$ of the companies had defined the role and responsibilities of the occupational health agent for the safety and health of staff at all levels.

Table 4: Percentage of enterprises implementing safety management practices in their workplaces

\begin{tabular}{ll}
\hline Occupational health and safety management practices & SMEs (\%) \\
\hline Written Health and safety policy & 44 \\
\hline Safety committee and technical protection & 69.7 \\
\hline Occupational health expert & 73.8 \\
\hline Accident report & 92.1 \\
\hline Accident investigation & 77.6 \\
\hline Budget for health and safety & 45.9 \\
\hline Job safety analyses & 60 \\
\hline
\end{tabular}

The results also demonstrated that $69.7 \%$ of the companies had technical protection and safety committees at their workplaces, and $73.8 \%$ of the enterprises had an occupational health expert working full-time or part-time for them. Moreover, $70.3 \%$ of the companies had a clear list of incidents, and $45.9 \%$ had an annual program to determine the occupational safety and health budget so as to reduce the rate of incidents. With respect to corrective measures taken to reduce incidents at the workplace, $60 \%$ of the companies had analyzed job safety and only $33.1 \%$ of them had made a booklet or catalogue of the safety performance of the company and distributed it among their workers.
The staff of the investigated enterprises obtained information regarding occupational safety and health at their workplace through different channels such as public relations boards $(80.7 \%)$, sessions $(76.3 \%)$, bulletins (52\%), booklets and pamphlets and other ways (37.9\%). With regard to occupational safety and health training, the results demonstrated that $64.7 \%$ of the companies provided occupational safety and health training for all their employees at all levels, $62.6 \%$ of the companies provided the training for new workers or workers starting a new job, and $72.3 \%$ of the target enterprises trained their staff on how to use PPE (Table 5).

Table 5: Percentage of enterprises providing safety training for workers

\begin{tabular}{ll}
\hline Safety training & SMEs (\%) \\
\hline Occupational health and safety training & 64.7 \\
\hline Safety training for new or changed workers & 62.6 \\
\hline Personal protective equipment training & 72.3 \\
\hline Training evaluation & 51.1 \\
\hline Training improvement after evaluation & 43.2 \\
\hline
\end{tabular}

\section{Discussion}

In order to increase the response rate of target enterprises, all questionnaires were collected from the occupational units of health centers in the city of Isfahan, and the additional information on the respondents were collected through phone calls. The average rate of response in this study was 59\%. Some questionnaires were returned because the receiver company's address had been changed. The other reason for the return of questionnaires was the fact that some 
companies feared that the questionnaire might be a kind of inspection or audit. Vassie et al. (2000) reported that in an opinion poll of Spanish and English SMEs, the rate of response regarding occupational safety and health was $11.45 \%$ to $13.9 \%$ (11). However, studies have demonstrated that people working in SMEs are more exposed to hazardous situations and work-related injuries and diseases than those working in major enterprises $(16,17)$. In order to monitor the environment of the target enterprises, visitors were appointed and sent to investigate the real condition of the participating companies.

Characteristics of the workforce of SMEs: The age of the male and female workers ranged between 19 and 62 and between 20 and 55 , respectively. The presence of older workers in the companies was probably because of their experience and skills or their wish to earn an income for their families. The minor (below 19 years old) and old (over 60 years old) workers are the most vulnerable groups; however, they do not constitute a considerable proportion of the workforce. Champoux and Brun (2003) maintained that the employees of small companies are generally younger, less literate, and less experienced than those of major companies, which might increase their workplace hazards (18). Because of their wish to have a higher income, workers of SMEs work overtime. Of the target enterprises, 12 companies permitted their workers to do more than 40 hours of overtime.

Facilities and amenities: According to our findings, $53.8 \%$ of companies did not have cafeterias or dining halls for their workers. Therefore, workers had to bring food to their workplace or find a place outside the workplace to have food. In $86.5 \%$ of the companies, there was a place for the staff to rest and sleep.

Fire prevention: Few companies (42 cases) were equipped with fire alarm and fire extinguishing systems, and provided fire extinguishing training, fire maneuvers, and rescue and evacuation training. All the above- mentioned items are obligatory based on the Iranian law for all Iranian industries. When a fire takes place, there is great loss of life and property. For example, a fire in Khorasan Textile Factory in 2013 killed 5 workers.

Electricity safety: The items in the questionnaire generally evaluated their accordance with the Iranian Labor Law. Hay (2002) reported that the laws in most Middle Eastern countries are mostly advisory and difficult to enforce in many cases (19). He mentioned, as an example, some regulations of Thailand's Ministry of Labor regarding electricity safety. He stated that those legal inconsistencies also existed in the Philippines (19).

Workplace hazards: To acquire exact and correct information about the target enterprises, some visitors were sent to the workplaces. This was done to realistically report the health hazards in the workplaces of enterprises. The visitors inspected the workplaces in terms of dust, heat, cold, noise, light, and etcetera by considering the work principles in Iran. As a result, the companies which still need to improve the conditions of their workplace were identified.

Controlling workplace hazards: Analysis of this section of the questionnaire was aimed at creating a real picture of the target industries. When some of the control measures taken by the companies were investigated, it was not clear whether those measures were effective or not. It was found, however, that $59.2 \%$ of the companies had controlled and monitored their workplaces to reduce hazards.

Occupational safety and health management and training: In fact, based on their size (number of employees), all SMEs must attempt to increase their compliance with safety and health regulations. For example, according to Iran's labor law, workshops with more than 25 employees must employ an occupational health expert. The results demonstrated that $44 \%$ of SMEs had regulated and written occupational safety and health policies (20). Brandshow et al. (2001) reported that $42.3 \%$ of the SMEs (less than 250 
employees) in the UK lacked a written safety and health policy. In a study by Massi et al. (2015), after interviewing 58 safety officers of SMEs, it was found that the most common impediments to occupational safety and health programs fell into three categories of regulations, resources, and information (8). A study by Legg et al. (2014) demonstrated that the intervention programs of occupational safety and health of the aspect of inspection are meant to increase consistency, help the stockholders of the industry recognize standards, and convey information to small enterprises (21).

The findings also demonstrated that $69.5 \%$ of the enterprises had a full-time or part-time occupational safety and health expert. Yet this was not the case for some of the companies $(26.2 \%)$, perhaps because the number of their employees was less than 25 . The findings also revealed that $23 \%$ of the target industries lacked an annual plan to determine their required budget to support safety and health programs. The results of this study were consistent in part with the results of the study by Kalantari et al. (2001). For example, in most enterprises, the employees were unaware of how to perform first aid in a timely and correct way during an incident. The difference of these two studies might lie in their data collection, size of target enterprises, the type of products, and etcetera. To improve the efficiency of occupational safety and health, strategies must be focused on challenged companies.

\section{Conclusion}

SMEs constitute a very important part of the economy of a country, because most of the workforce is employed by those enterprises. The problems of some of the enterprises investigated in this study were related to the market condition, technological limitations, and management issues. Iran's Ministry of Industries and Business has maintained that Iran Small and Medium Industries Organization have plans to enhance those industries in order to support technology and employees' health. The rate of response of SMEs was almost average. Considering the characteristics of the workforce, a small number of target industries had employed minor (below 19 years old) and old (over 60 years old) workers who are the most vulnerable groups. Many employees worked overtime to earn more income. Facilities and amenities and health management of SMEs were sufficient. With regard to fire prevention, very few enterprises had fire alarm systems and fire extinguishers, and provided fire extinguishing training, fire extinguishing practices, and training on evacuation during fire. With respect to occupational safety and health management, it can be inferred from this study that essential safety factors for SMEs include reporting incidents, investigating incidents, and inspecting safety, because $80 \%$ of the target enterprises perform these activities. To improve the efficiency of occupational safety and health, strategies must be focused on challenged companies.

\section{Acknowledgements}

The authors wish to express their gratitude to Iran's Ministry of Labor and Social Affairs, Social Security Organization, Isfahan University of Medical Sciences, and the health centers in Isfahan for collaborating with the authors, and Mr. Khodaei for his help in data analysis.

Conflict of interests: None declared.

\section{References}

1. Karimi F, Sagheb H. Survey the status and position of small industries of Isfahan in the country. Commercial Surveys 2009; 7(37):6482.

2. Allahyari T, Tirgar A, Kuhpayehei A, Alimohammadi I. Occupational health. $1^{\text {st }}$ ed. Tehran: Andisheh Rafi; 2009. P.17.

3. Iran. Statistical Center. The results of the survey of the country's industrial workshops 49- 10 employees. Statistical Center of Iran, Statistics by Topic, Industry and Mining Report; 2011. Availble from: 
https://www.amar.org.ir/Portals/0/Files/fulltext /1389/n_10-49nafar_89.pdf

4. Targoutzidis A, Koukoulaki T, Schmitz-Felten E, Kuhl K, Oude Hengel KM, Rijken E, et al. The business case for safety and health: costbenefit analyses of interventions in small and medium-sized enterprises. Luxembourg: Publication Office of the European Union, European Agendy for Safety and Health at Work; 2014.

5. Taheri Namoghi M. Surveying the condition of occupational safety and hygiene in manufacturing and technical trade units in Sabzevar. Medical Science Journal of Islamic Azad University Tehran Medical Branch 2006; 16(2):113-8.

6. Iran. Statistical Center. The results of the survey of industrial workshops 10 employees and more. Statistical Center of Iran, Statistics by Topic, Industry and Mining Report; 2011. Availble from: https://www.amar.org.ir/Portals/0/Files/fulltext /1389/n_10nafar_89.pdf

7. Antonsson $\mathrm{AB}$, Birgersdotter L, BornbergerDankvardt S. Small enterprises in Sweden: Health and safety and the significance of intermediaries in preventive health and safety. Stockholm, Sweden: National Institute for Working Life; 2002. 64p. Report No.:NR 2002:I

8. Masi D, Cagno E. Barriers to OHS interventions in small and medium-sized enterprises. Saf Sci 2015; 71(Part C):226-41.

9. Jørgen Limborg H, Grøn S, Flensborg Jensen M. Research Note: Networking among small and medium-sized enterprises: Meeting the challenge of promoting safety and health measures. Small Enterprise Research 2014;21(2):214-22.

10. Floyde A, Lawson G, Shalloe S, Eastgate R, D'Cruz M. The design and implementation of knowledge management systems and elearning for improved occupational health and safety in small to medium sized enterprises. Saf Sci 2013; 60:69-76.

11. Vassie L, Tomàs JM, Oliver A. Health and safety management in UK and Spanish SMEs: a comparative study. J Safety Res 2000;
31(1):35-43

12. Kongtip P, Yoosook W, Chantanakul S. Occupational health and safety management in small and medium-sized enterprises: An overview of the situation in Thailand. Saf Sci 2008; 46(9):1356-68.

13. Wei L, Shi-da W. Occupational health management and service for small-scale industries in Shanghai. Toxicology 2004; 198(1-3):55-61.

14. Park H, Ha E, Kim J, Jung H, Paek D. Occupational health services for small-scale enterprises in Korea. Ind Health 2002; 40(1):16.

15. Kalantari F, Majmae N, Habibi E. Survey the status of available of health occupational in small workshops of Car service in Isfahan in the years 2001-2002. Paper presented at: The National Congress of Medical and Paramedical Sciences; 2005 Jan 11-12; Isfahan, Iran.

16. Masi D, Enrico C. Barriers to OHS interventions in small and medium-sized enterprises. Saf Sci 2015; 71(Part C):226-41.

17. Micheli GJL, Cagno E. Dealing with SMEs as a whole in OHS issues: warnings from empirical evidence. Saf Sci 2010; 48(6):72933.

18. Champoux D, Brun JP. Occupational health and safety management in small size enterprises: an overview of the situation and avenues for intervention and research. Saf Sci 2003; 41(4):301-18.

19. Hay D. Strengthening of labour standards in selected developing member countries. Regional Review: Occupational Safety and Health. Mandaluyong, Metro Manila, Philippines: Asian Development Bank. 2002 Sep. 42 P. Report No.: ADB/ILO RETA Project No. 5887.

20. Bradshaw LM, Fishwick AD, Eskin F, Fishwick D. Provision and perception of occupational health in small and medium-sized enterprises in Sheffield, UK. Occup Med (Lond) 2001; 51(1):39-44.

21. Legg SJ, Olsen KB, Laird IS, Hasle P. Managing safety in small and medium enterprises. Saf Sci 2015; 71(Part C):189-96. 